\title{
Arm Span and Its Relation to Height in a 2- to 17-Year-Old Reference Population and Heterozygous Carriers of ACAN Variants
}

\author{
Willem J.M. Gerver ${ }^{a}$ Alexandra Gkourogianni ${ }^{b}$ Andrew Dauberd, e \\ Ola Nilsson $^{\text {b, c }}$ Jan M. Wit ${ }^{f}$
}

${ }^{a}$ Department of Paediatrics, Maastricht University Medical Centre, Maastricht, The Netherlands; ${ }^{b}$ Division of Paediatric Endocrinology and Centre for Molecular Medicine, Karolinska Institutet and University Hospital, Stockholm, Sweden; ' Department of Paediatrics, School of Medical Sciences, Örebro University and University Hospital, Örebro, Sweden; d Division of Endocrinology, Children's National Hospital, Washington, DC, USA; e Department of Pediatrics, George Washington University School of Medicine and Health Sciences, Washington, DC, USA; fDepartment of Paediatrics, Leiden University Medical Centre, Leiden, The Netherlands

\section{Keywords}

Arm span · Growth · ACAN · Anthropometry · Body proportions

\begin{abstract}
Background/Objectives: In the clinical assessment of a short or tall child, estimating body disproportion is useful to assess the likelihood of a primary growth disorder, e.g., skeletal dysplasia. Our objectives were (1) to use data from the Maastricht study on healthy children (2-17 years) to calculate relative arm span (AS) for height $(\mathrm{H})$ to serve as age references for clinical purposes; (2) to assess its age and sex dependency; and (3) to investigate relative AS adjustment for age and sex in individuals with ACAN haploinsufficiency. Methods: The Maastricht study data (2,595 Caucasian children, 52\% boys, $48 \%$ girls) were re-analysed to produce reference tables and graphs for age and sex of AS - $\mathrm{H}$ and AS/H. Published information on $\mathrm{AS} / \mathrm{H}$ in Europeans was used as reference data for adults. Relative AS from 33 patients with ACAN haploinsufficiency were plotted against reference data and expressed as standard deviation score (SDS) for age and sex. Results: Mean AS - H from 2 to 17 years increased from -1.2 to $+1.5 \mathrm{~cm}$ in boys and from -4.8 to $+1.6 \mathrm{~cm}$ in girls. Mean
\end{abstract}

\begin{tabular}{ll}
\hline karger@karger.com & ( ) 2020 The Author(s) Karger \\
www.karger.com/hrp & Published by S. Karger AG, Basel Open access \\
& This article is licensed under the Creative Commons Attribution- \\
Karger & NonCommercial-NoDerivatives 4.0 International License (CC BY- \\
NC-ND) (http://www.karger.com/Services/OpenAccessLicense). \\
Usage and distribution for commercial purposes as well as any dis- \\
tribution of modified material requires written permission.
\end{tabular}

AS/H increased from 0.9848 to 1.0155 in boys and from 0.9468 to 1.0028 in girls. Mean AS/H in patients with ACAN haploinsufficiency was approximately 1.0, 1.5 and 0.5 SDS in young children, adolescents and 20- to 50-year-olds, respectively, and normal thereafter. Conclusions: These reference charts can be used for 2- to 17-year-old children/adolescents. Carriers of ACAN haploinsufficiency have an elevated mean AS/H in childhood and adolescence and a slightly elevated ratio till 50 years.

(c) 2020 The Author(s) Published by S. Karger AG, Basel

\section{Introduction}

The process that transforms a newborn into an adult (growth) implies not only an increase in size but also in shape. The reason is that in the growing child, the increase of different parts of the body does not occur simultaneously nor at the same speed. Therefore, the interrelationship of a number of linear measurements changes over time between birth and adulthood.

The usual method of judging body shape is to assess "body proportion," which is usually translated into the 
relationship between size of the trunk and size of the long bones. The father of paediatric endocrinology, Lawson Wilkins, advocated to measure the "lower segment" (the distance from the pubic bone to the floor, thus a direct indicator of leg length) and calculate the "upper segment" (deducted indicator of spine plus head) by subtracting lower segment from height $(\mathrm{H})$ [1]. The ratio between upper and lower segment was then used as an indicator of body (dis)proportion, and some reference studies have been performed [2-5]. Later, another giant of paediatric endocrinology, James Tanner, advocated to measure sitting height ( $\mathrm{SH})$ (direct indicator of trunk plus head), calculate leg length by subtracting $\mathrm{SH}$ from height in relation to height, and use the $\mathrm{SH} / \mathrm{H}$ ratio as an indicator of (dis)proportion [6]. This method is believed to be more accurate, and from several countries reference charts for the $\mathrm{SH} / \mathrm{H}$ ratio have been reported [7-11].

Another anthropometric measure to objectify the relationship between trunk and long bones is arm span (AS), the summation of arm length and thoracic width, and relate this to stature. It is relatively easy to measure but still uncommonly assessed in clinical practice. The relationship between AS and height ("relative AS") can be expressed as $\mathrm{AS} / \mathrm{H}$ ratio [12], AS minus height (AS - H) [5] or as AS for height [13]. Relative AS has been proposed as a useful measure in the assessment of children with short stature, primarily as an indicator of a skeletal dysplasia (e.g., SHOX haploinsufficiency [12]) or of syndromic tall stature (e.g., Marfan syndrome [14]). However, there is a scarcity of accurate reference data and it is unclear whether the ratio $(\mathrm{AS} / \mathrm{H})$ or the difference $(\mathrm{AS}-\mathrm{H})$ is to be preferred. The limited data on the effect of age, sex and ethnicity suggest that AS grows proportionally more than stature in children until about age 15 years in females and about age 25 years in males. Thereafter AS/H reaches a plateau until about age 45 years, when the ratio increases almost linearly with age to 1.025 and 1.020 in European males and females, respectively. In Asia, Iran and Ghana, AS/H is considerably higher than in Europeans over the whole age range, up to 1.07 in middle-aged Ghanese men [15].

In most forms of short-limb skeletal dysplasias, the information obtained from the $\mathrm{SH} / \mathrm{H}$ ratio is similar compared with information from relative AS, indicating that leg growth parallels arm growth. However, there appears to be one exception: children with a heterozygous variant of the gene encoding aggrecan $(A C A N)$ present with short legs (increased mean $\mathrm{SH} / \mathrm{H}$ ratio), but $\mathrm{AS}-\mathrm{H}$ is close to zero and even positive in adult carriers [16].

Because of the clinical usefulness of AS/H or AS $-\mathrm{H}$, our first objective was to use the data from the original study population of the atlas Paediatric Morphometrics by Gerver and de Bruin [13] to calculate the distribution of these 2 indicators in healthy boys and girls, to serve as an age reference for clinical purposes. Secondly, we wished to assess a possible age and sex dependency as observed in various populations in the world [15] and in Turkish 4- to 18-year-olds [5]. The third objective of this study was to investigate if adjustment for age and sex would change the conclusions of the study in patients with $A C A N$ haploinsufficiency, which suggested normal or even increased relative AS in such patients [16].

\section{Patients and Methods}

\section{Reference Population}

The mixed-longitudinal Maastricht II study was performed in 1995 and consisted of 2,595 Caucasian children (1,349 [52\%] boys and 1,246 [48\%] girls), measured from 0 to 17 years of age. Children suspected of a pathological cause of abnormal growth were excluded. No information on place of birth of the parents nor on ethnicity was collected. In Maastricht (118,000 inhabitants), the percentage of non-European immigrants in 2010 was $7.8 \%$. Further details about this study population have been reported previously [17]. For this analysis, only the first measurements of the participants were used.

Height was measured using the Harpenden stadiometer after removing shoes and socks. The top of the head was in contact with the headboard, and a $0.5-\mathrm{kg}$ weight was placed on the headboard. This served the purpose of flattening the child's hair and freed the physician's hands enabling him to keep the child in the correct upright position. The child's head was held in the "Frankfurter plane" (the lower borders of the orbits in the same horizontal plane as the external auditory meatus). The measurements were taken while a gentle upward pressure was exerted on the mastoid processes so that the child was fully extended. In older children, stretching was achieved by telling them to breathe deeply [13]. To measure AS, the Harpenden anthropometer was used. The child was measured standing with the arms fully extended. The distance between the tips of the stretched middle fingers was taken.

\section{Construction of the Reference Charts}

The total population of children was sorted in ascending order, and by means of a cubic spline approximation, the $\mathrm{m}=\mathrm{P}_{50}$ was estimated for each sex separately. Thereafter, the population was divided in a number of subsets of 100 children. For each subset, the standard deviation (SD) was estimated, revealing a large number of $S D$ values. Again, a cubic spline approximation was applied to get the $\mathrm{m}=\mathrm{P}_{50}$ of the SD values. From these $\mathrm{P}_{50}$ lines for mean and $\mathrm{SD}$, one can read back the exact value at any age. For more details, see Gerver and de Bruin [13].

Reference Values Beyond the Age of 17 Years

The Maastricht study population ends at age 17 years. Beyond that age, the data from European individuals participating in the study of Quanjer et al. [15] were used as a reference. In this study, the AS/H ratios from 13,947 subjects aged 5-99 years were analysed, 
Table 1. Arm span minus height and divided by height of the Maastricht reference population

\begin{tabular}{|c|c|c|c|c|c|c|c|c|}
\hline \multirow[t]{3}{*}{ Age, years } & \multicolumn{4}{|l|}{ Boys } & \multicolumn{4}{|l|}{ Girls } \\
\hline & \multicolumn{2}{|c|}{$\begin{array}{l}\text { arm span minus height, } \\
\mathrm{cm}\end{array}$} & \multicolumn{2}{|c|}{ arm span divided by height } & \multicolumn{2}{|c|}{$\begin{array}{l}\text { arm span minus } \\
\text { height, } \mathrm{cm}\end{array}$} & \multicolumn{2}{|c|}{$\begin{array}{l}\text { arm span divided by } \\
\text { height }\end{array}$} \\
\hline & $\mathrm{P}_{50}$ & SD & $\mathrm{P}_{50}$ & SD & $\mathrm{P}_{50}$ & SD & $\mathrm{P}_{50}$ & SD \\
\hline 2 & -1.23 & 2.46 & 0.9848 & 0.0213 & -4.77 & 2.32 & 0.9468 & 0.0206 \\
\hline 3 & -1.40 & 2.57 & 0.9859 & 0.0213 & -4.19 & 2.39 & 0.9547 & 0.0206 \\
\hline 4 & -1.45 & 2.62 & 0.9872 & 0.0212 & -3.64 & 2.41 & 0.9620 & 0.0205 \\
\hline 5 & -1.37 & 2.73 & 0.9887 & 0.0212 & -3.11 & 2.52 & 0.9687 & 0.0205 \\
\hline 6 & -1.19 & 2.84 & 0.9904 & 0.0211 & -2.59 & 2.63 & 0.9748 & 0.0204 \\
\hline 7 & -0.94 & 2.95 & 0.9923 & 0.0211 & -2.11 & 2.75 & 0.9803 & 0.0204 \\
\hline 8 & -0.63 & 3.06 & 0.9944 & 0.0210 & -1.64 & 2.86 & 0.9852 & 0.0203 \\
\hline 9 & -0.28 & 3.16 & 0.9967 & 0.0210 & -1.19 & 2.98 & 0.9895 & 0.0203 \\
\hline 10 & 0.08 & 3.27 & 0.9992 & 0.0209 & -0.77 & 3.09 & 0.9932 & 0.0202 \\
\hline 11 & 0.44 & 3.38 & 10.019 & 0.0209 & -0.37 & 3.20 & 0.9963 & 0.0202 \\
\hline 12 & 0.78 & 3.49 & 10.048 & 0.0208 & 0.01 & 3.32 & 0.9988 & 0.0201 \\
\hline 13 & 1.09 & 3.60 & 10.079 & 0.0208 & 0.36 & 3.43 & 10.007 & 0.0201 \\
\hline 14 & 1.33 & 3.71 & 10.112 & 0.0207 & 0.70 & 3.55 & 10.020 & 0.0200 \\
\hline 15 & 1.49 & 3.82 & 10.142 & 0.0207 & 1.01 & 3.66 & 10.027 & 0.0200 \\
\hline 16 & 1.55 & 3.86 & 10.150 & 0.0213 & 1.31 & 3.77 & 10.028 & 0.0206 \\
\hline 17 & 1.49 & 3.90 & 10.155 & 0.0213 & 1.58 & 3.89 & 10.028 & 0.0206 \\
\hline
\end{tabular}

from 9 centres over the world. The purpose of the study was to establish a multi-ethnic, all-age prediction equation for estimating stature from AS. For the European population, data from France, Turkey, Serbia and Montenegro were collected from 4,531 subjects. Unfortunately, we only had access to the graphical presentation of the mean $\mathrm{AS} / \mathrm{H}$ and had to estimate the ratios at different ages from the graphs. For each individual patient with an $A C A N$ variant, the AS/H ratio SD score (SDS) for age and sex was calculated by estimating the mean ratio at the appropriate age from the graphs published by Quanjer et al. [15] and using the SD at 17 years from the Maastricht population.

\section{Patients Carrying Heterozygous Aggrecan Gene (ACAN)}

Variants

The ACAN study was performed in 2016-2017 by a large consortium of paediatric endocrinologists and investigators and consisted of 103 ACAN mutation-positive individuals (57 females and 46 males) from 20 different families with dominant short stature due to heterozygous pathogenic variants [16]. From this initial cohort, all 33 individuals with simultaneous height, SH and AS measurements at minimally 1 time point were selected. The study population consisted of 14 children/adolescents ( 5 females, 9 males, age range $4.58-15.08$ years) and 19 adults ( 12 females, 7 males, age range $18-81$ years).

\section{Results}

\section{Relative AS in Healthy Children}

We first tested whether the distribution of the data was sufficiently Gaussian according to the technique pub- lished previously [18], which proved to be the case (data not shown).

There was a highly significant correlation between AS and height in both sexes: for boys: AS $=0.9374 \times \mathrm{H}+$ $8.6155\left(R^{2}=0.9807\right)$ and for girls: $\mathrm{AS}=0.9259 \times \mathrm{H}+$ $11.298\left(R^{2}=0.9819\right)$, as shown in online supplementary Figure 1a, b (for all online suppl. material, see www. karger.com/doi/10.1159/000508500). For boys, the $\beta$ coefficient of the linear regression formula is -9.8 with a $95 \%$ confidence interval of $(-11.3 ;-8.4)$ and for girls -11.9 with a $95 \%$ confidence interval of $(-13.5 ;-10.3)$. Using a univariate analysis of variance, there was no significant difference between the regression slopes of the models for boys and girls $(p=0.467)$.

Table 1 shows the mean and SD for AS $-\mathrm{H}$ and AS/H ratio for age at full years for boys and girls. Graphical representations (reference charts) for AS - $\mathrm{H}$ are shown in Figure $1 \mathrm{a}, \mathrm{b}$. The increase of the mean value between 2 and 17 years in our study in boys $(2.7 \mathrm{~cm})$ is similar to the increase observed in Turkish children $(3.1 \mathrm{~cm})$. In contrast, the increase observed in girls $(6.4 \mathrm{~cm})$ is considerably larger than observed in Turkish children $(2.1 \mathrm{~cm})$ [5], predominantly caused by the lower AS $-\mathrm{H}$ at 2 years of age in our study. The age at which AS $-\mathrm{H}=0$ in the Maastricht population is 10 and 12 years for boys and girls, respectively. AS - $\mathrm{H}$ is constant at $1.5 \mathrm{~cm}$ from the age of 15 years in boys, while it increases to $1.6 \mathrm{~cm}$ at the 
Fig. 1. Arm span minus height of the Maastricht reference population for boys (a) and girls (b).

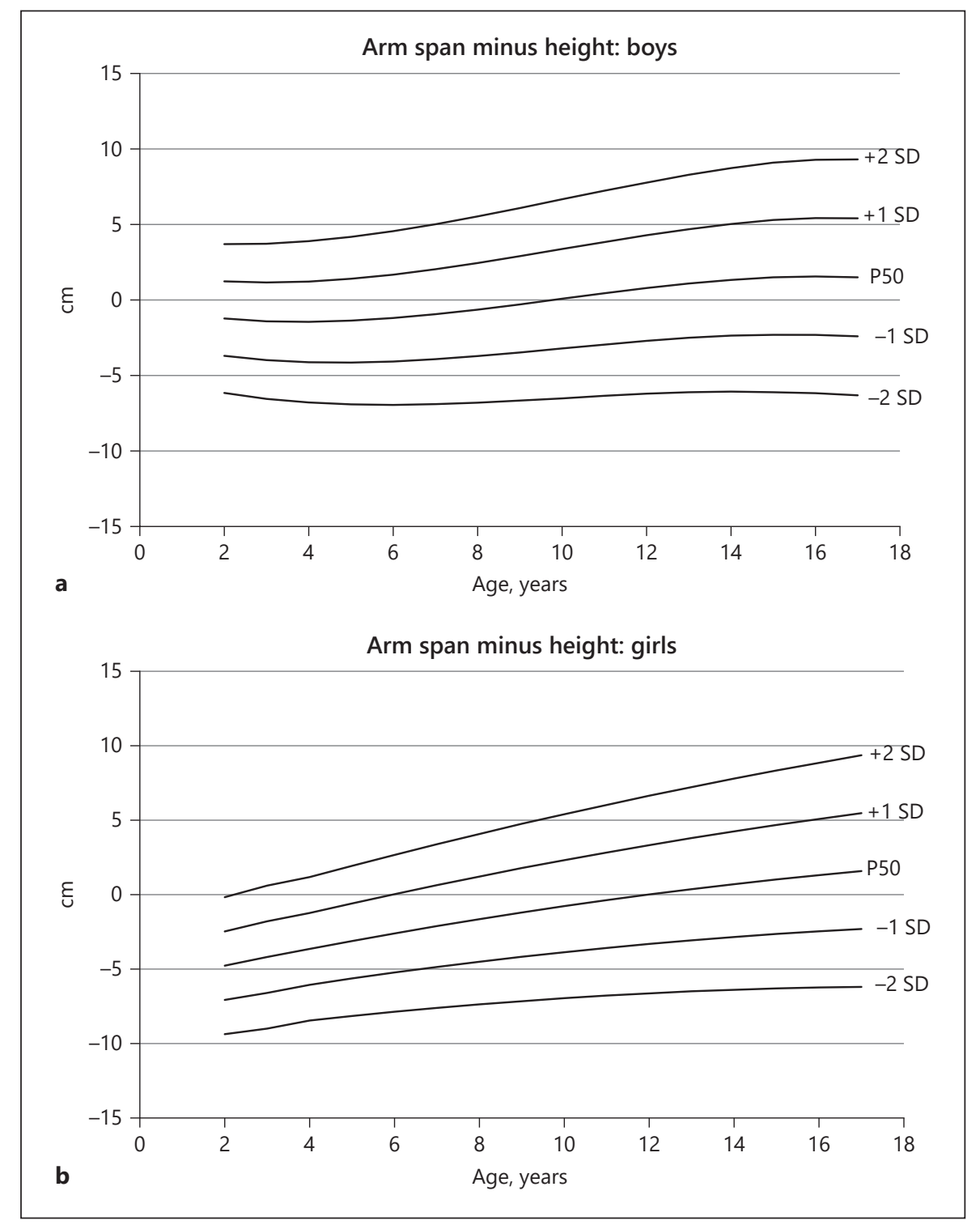

age of 17 years in girls. Reference charts for AS/H are presented in Figure 2a, b. As expected, the age at $\mathrm{AS} / \mathrm{H}=1$ is similar as observed for AS $-\mathrm{H}=0$. AS/ $\mathrm{H}$ is nearly constant from 15 years in boys and girls.

\section{Relative AS in Heterozygous Carriers of ACAN Variants}

The data from 33 individuals carrying heterozygous $A C A N$ variants reported previously [16] were re-analysed adjusting for reference data from healthy controls. For the calculation of SDS for $\mathrm{AH}-\mathrm{H}$ and $\mathrm{AS} / \mathrm{H}$ in children up to 17 years, we used the formulas derived from the Maastricht study. Beyond 17 years, AH - H SDS was based on mean and SD at 17 years in the Maastricht study.
AH/H SDS was based on mean values of the European population estimated from the graphs of Quanjer et al. [15] and the SD derived from 17-year-olds in the Maastricht study. Individual data are presented in online supplementary Table 1.

Figure 3 shows the AS for height in individuals with $A C A N$ haploinsufficiency, with a regression equation of $\mathrm{AS}=1.07 \times \mathrm{H}-4.06\left(R^{2}=0.98\right)$ in males and $\mathrm{AS}=1.08$ $\times \mathrm{H}-12.20\left(R^{2}=0.96\right)$ in females. In subjects with a height $<110 \mathrm{~cm}$, AS is equal to height, while above 140 $\mathrm{cm}$, AS exceeds height.

Data on AS - H SDS (Fig. 4a) show an average SDS of approximately +1 up to 50 years of age. Data on $\mathrm{AS} / \mathrm{H}$ SDS (Fig. 4b) show an average value of 1 SDS in 2- to 
Fig. 2. Arm span/height of the Maastricht reference population for boys (a) and girls (b).
Arm span divided by height: boys

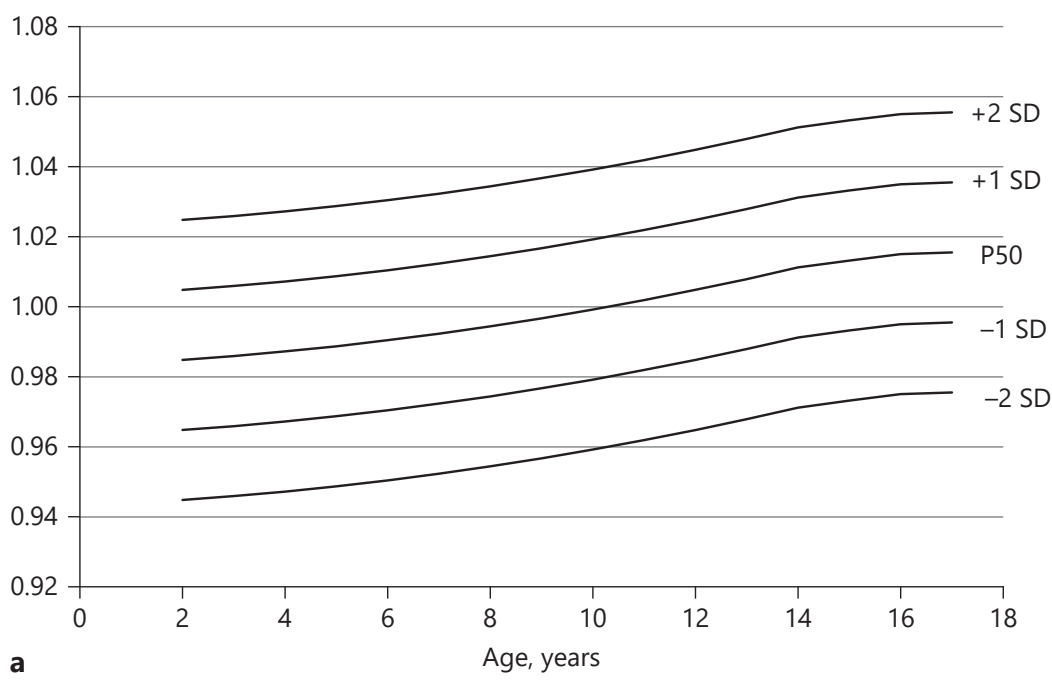

Arm span divided by height: girls

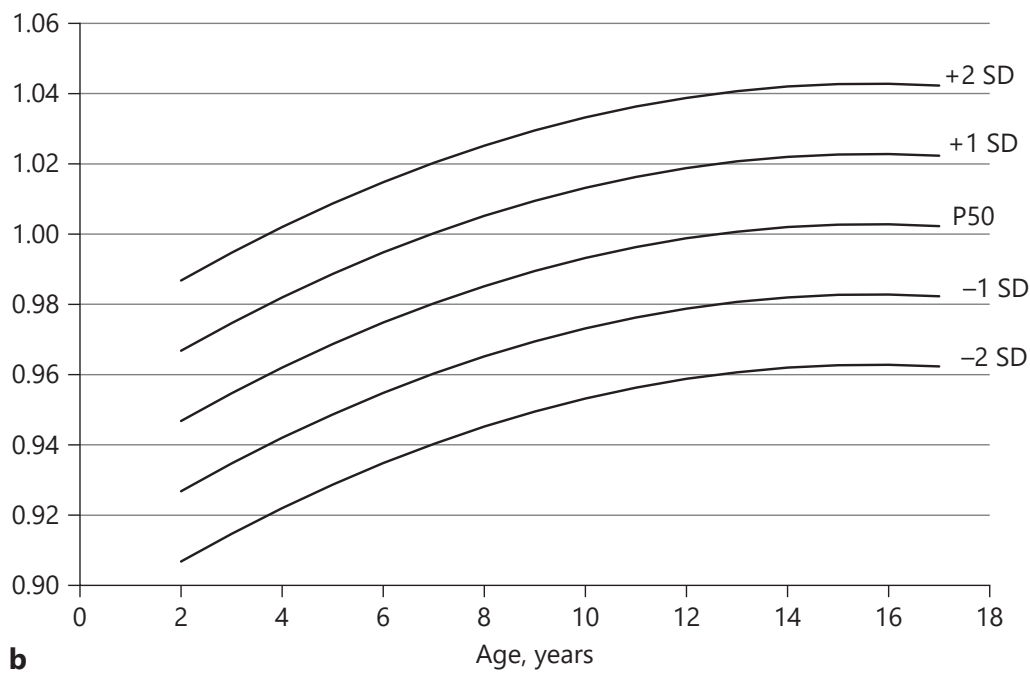

10-year-old children, increasing to 1.5 SDS in teenagers, followed by a mean of 0.5 SDS in 20 - to 50 -year-olds and normal values beyond 50 years.

\section{Discussion}

This report presents reference charts for AS - $\mathrm{H}$ and AS/ $\mathrm{H}$ for children aged 2-17 years based on the 2001 Maastricht study, which can be used as a clinical tool at physical examination of short or tall children. We confirm the positive age dependency suggested by previous publications $[5,15]$ and show a mean increase of AS $-\mathrm{H}$ from -1.2 to $+1.5 \mathrm{~cm}$ in boys and from -4.8 to $+1.6 \mathrm{~cm}$ in girls. In boys, this increase is similar to the increase reported for Turkish children, but in girls it is clearly more pronounced [5]. We have no explanation for the difference between boys and girls but speculate that below the age of 4 years the accuracy of measurements is suboptimal because of problems to fully stretch the arms.

In paediatric patients with a heterozygous $A C A N$ variant, $\mathrm{AS} / \mathrm{H}$ was approximately +1 SDS below 10 years of age, and +1.5 SDS in teenagers. The increase in adolescence may be associated with the premature closure of epiphyseal growth plates in this condition [16]. In 20- to 50 -year-old adults, the mean AS/H is 0.5 SDS followed by 


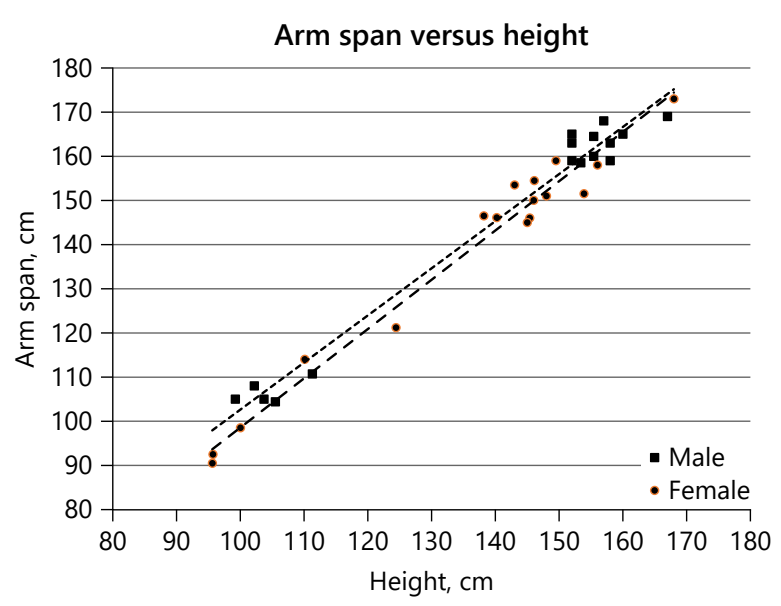

Fig. 3. Arm span versus height in the individuals heterozygous for $A C A N$ variants. The correlation is arm span $=1.0084 \times$ height 1.8238 .

a normal ratio in a small number of older individuals, when adjusted for age and sex according to European reference data [15]. We, therefore, confirm that children and adolescents with $A C A N$ haploinsufficiency tend to have relatively long AS, but in contrast to the conclusions in the previous paper [16], this is predominantly observed in childhood and adolescence, gradually normalizing in adulthood. However, further studies including a larger number of elderly individuals are needed to confirm this finding. Taken together with previous observations that children with ACAN mutations tend to have short legs, these findings suggest that the weight-bearing growth plates of the legs are more affected than the less loaded growth plates of the arms in the phase of linear growth. However, since AS also includes thoracic width, the relatively long AS may also be caused by a broad thoracic width. Future studies on direct measurements of arm lengths and thoracic width are necessary to distinguish between these alternative explanations. Since mean AS/H in adult carriers is only slightly increased compared with the age- and sex-adjusted reference, the elevated AS/H SDS below 20 years may be at least partly due to advanced bone maturation.

An abnormal $\mathrm{SH} / \mathrm{H}$ ratio is an important feature at physical examination of children and adults with short or tall stature $[8,19]$, since it is suggestive for a form of skeletal dysplasia or syndromic tall stature. Its importance has increased in the last decade when several relatively mild skeletal dysplasias were discovered caused by haploinsufficiency of SHOX, NPR2, ACAN, IHH and NCCP

Arm Span for Height in Controls and Carriers of ACAN Variants (for reviews, see $[19,20]$ ). In carriers of such variants, an increased mean $\mathrm{SH} / \mathrm{H}$ ratio SDS was one of the crucial clinical features. At the other end of the spectrum, a decreased $\mathrm{SH} / \mathrm{H}$ ratio in a short child indicates the presence of rare skeletal dysplasias characterized by diminished vertebral growth, such as observed in children with a homozygous PAPSS2 variant [21].

AS is the most common way to estimate arm length. An inherent weakness of AS is that by measuring the span of the stretched arms, the width of the trunk is included, while one may be primarily interested in a measure of growth of the long bones alone. However, in healthy children, the proportion of arm length and thoracic width appears to be constant in childhood and adolescence, with no perceivable effect of puberty [13]. Direct measurements of the long bones of arms and legs can be done accurately, but this needs special expertise to know its bony marks and is not feasible in most clinical circumstances.

Besides these 2 measures associated with body shape, many more can be performed, resulting in several other indices. For more information, we refer to the atlas Paediatric Morphometrics of Gerver and de Bruin [13] of which a digital version is available on request (w.gerver@ maastrichtuniversity.nl). With regard to AS, in this atlas anthropometric reference tables and charts are presented on AS as a function of age and height in healthy children and adolescents of 2-17 years, but not on AS $-\mathrm{H}$ or AS/H ratio versus age.

In pulmonology, the $\mathrm{AS} / \mathrm{H}$ has been used as a proxy for height to adjust forced expiratory volume in 1 second. Recently, reference values for age and sex for 4 regions of the world (Europe, Asia, Ghana and Iran) were reported [15]. In that study, AS was shown to grow proportionally more than stature in children until age 15 years in females and age 25 years in males. Thereafter, the mean AS/H ratio shows a plateau until about age 45 years, when the ratio slightly increases with age, almost linearly. The difference between boys and girls was explained as a reflection of the higher levels of oestrogens in girls, which stimulates secondary sexual characteristics as well as epiphyseal fusion. In the paper by Quanjer et al. [15], the mean AS/H at 17 years is about 1.01 and 1.005 in boys and girls, respectively, similar to the values obtained in the Maastricht population (1.0155 in boys and 1.0028 in girls). In 15 - to 40 -year-old females, the mean $\mathrm{AS} / \mathrm{H}$ ratio is approximately 1.005 , consistent with the 15 - to 17 -year-olds in the Maastricht population. For males, the mean $\mathrm{AS} / \mathrm{H}$ slowly increases between 17 and 30 years of age, followed by stabilization at approximately 1.02. Between 40 and 80 
Fig. 4. Arm span minus height SDS (a) and arm span/height ratio SDS (b) in individuals heterozygous for $A C A N$ variants. Up to 17 years, we used mean and SD from the Maastricht population. For arm span minus height beyond 17 years, the mean and $\mathrm{SD}$ at 17 years of the Maastricht population were used. For arm span/height ratio beyond 17 years, we used estimated mean values from Quanjer et al. [15] and SD values from the Maastricht population at 17 years.

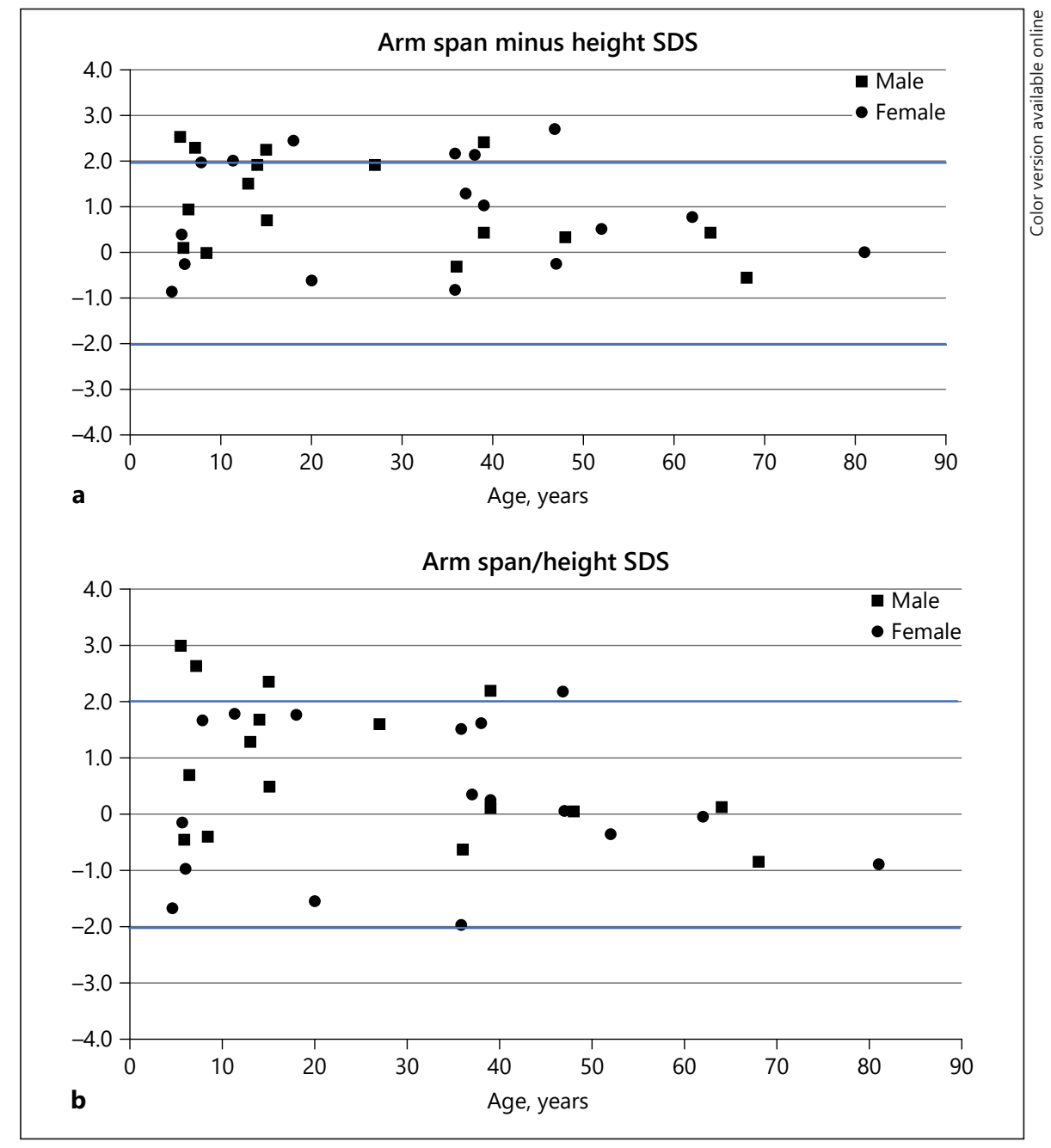

years, the mean $\mathrm{AS} / \mathrm{H}$ slightly increases to 1.025 in males and 1.02 in females.

In anthropometry, the use of ratios is popular, but one has to realize that a simple ratio of 2 measurements can be misleading. The ratios observed in 2 individuals may be equal, while their numerators and denominators are not. This problem can be overcome when considering the original measurements as pairs of variables. A combination of 2 variables can be outside the normal range even when the separate components are within the normal range. It is also possible for each of 2 variables to be outside their separate normal ranges but for the combination to be normal. Therefore, in this study, the relative AS is presented not only as AS/ $\mathrm{H}$ and $\mathrm{AS}-\mathrm{H}$, but also as a function of height.

In general, AS correlates well with height at all ages as illustrated in online supplementary Figure 1. Mean AS/H changes from 0.99 to 1.02 in boys and from 0.95 to 1.00 in girls, in a regular way, and there is no sign of any change during puberty. A similar change is seen for AS - $\mathrm{H}$ that shows a change from negative to positive values with a transition at the age of 10 and 12 years in boys and girls, respectively. In childhood and adolescence, both indicators of relative AS can be used, but because of the absence of normative data in adulthood for $\mathrm{AS}-\mathrm{H}$, we believe that for future studies AS/ $\mathrm{H}$ would be the more useful index.

In conclusion, our observations offer some refinement of the findings in the previous paper by members of our team [16], where a heterozygous $A C A N$ variant appeared to be associated with a normal AS - $\mathrm{H}$ in childhood and elevated AS - $\mathrm{H}$ in adulthood. After adjustment for age and sex, our present interpretation is that mean $\mathrm{AS} / \mathrm{H}$ SDS is elevated in children below 10 years (1 SDS), slightly more elevated in teenagers (1.5 SDS, possibly associated with advanced maturation of the epiphyseal growth plates), mildly elevated (0.5 SDS) in 20- to 50-year-olds 
and appears to be normal beyond 50 years. This implies that the effect of $A C A N$ haploinsufficiency indeed shows a discrepancy between the 2 indicators of body disproportion $(\mathrm{SH} / \mathrm{H}$ and $\mathrm{AS} / \mathrm{H})$, but to a lesser extent than assumed on the basis of the AS - H index, and more in the paediatric population than in adults.

\section{Acknowledgement}

We thank all the participants and their families for their participation as well as the International Aggrecan Consortium for contributing anthropometric data.

For the reference data, we thank all children and adolescents of Maastricht and its surrounding region who agreed to have their body measures assessed, which formed the basis of the atlas Paediatric Morphometrics. We also thank the medical students and Angele Gerver-Jansen who were instrumental to collect these data during several years.

\section{Statement of Ethics}

The regional ethical review board of Umeå University (Umeå, Sweden) and Karolinska Institutet (Stockholm, Sweden) approved the present study. All the participants or their legal guardians provided written informed consent.

\section{Disclosure Statement}

W.J.M.G. and A.G. have nothing to disclose. A.D. has received speakers' honoraria from Pfizer, Novo Nordisk, Sandoz, Versartis, Ipsen and Merck KGaA and consulting fees from Ascendis and Ipsen. A.D. has received research support from Novo Nordisk and Ipsen. O.N. has received speakers' honoraria from Pfizer, Lilly, Abbott and Biomarin, consulting fees from Ascendis and KyowaKi- rin, and research support from KyowaKirin and the Novo Nordisk Foundation. J.M.W. has received speakers' honoraria from Pfizer, Versartis, Sandoz, Lilly, Merck, JCR, Ipsen and Novo Nordisk and consulting fees from Merck, Aeterna Zentaris and Agios.

\section{Funding Sources}

W.J.M.G. and J.M.W. report no funding sources. The work of A.D. was supported by the Eunice Kennedy Shriver National Institute of Child Health and Human Development at the National Institutes of Health (Grant 1K23HD073351). The work by O.N. and A.G. was supported by grants from the Swedish Research Council (project K2015-54X-22 736-01-4 \& 2015-02227), the Swedish Governmental Agency for Innovation Systems (Vinnova) (2014-01438), Marianne and Marcus Wallenberg Foundation, IngaBritt och Arne Lundbergs forskningsstiftelse, Byggmästare Olle Engkvist Stiftelse, the Swedish Society of Medicine, Erik och Edith Fernström Foundation for Medical Research, Nyckelfonden, Stiftelsen Frimurare Barnhuset i Stockholm, the Stockholm County Council, Karolinska Institutet, Stockholm, Sweden, and Örebro University, Örebro, Sweden.

\section{Author Contributions}

W.J.M.G. conducted the Maastricht growth study, performed all calculations, prepared all Figures and Tables and revised consecutive versions of the manuscript. A.G. conducted the study on ACAN patients, supplied relevant growth data to W.J.M.G. and revised consecutive versions of the manuscript. A.D. conducted the study on ACAN patients and revised the manuscript. O.N. planned and managed the collection of data of $A C A N$ patients, selected and verified relevant growth data and revised consecutive versions of the manuscript. J.M.W. initiated the study, advised on the preparation of Figures and Tables, and wrote consecutive versions of the manuscript. Before submission, all authors consented with the final version of the manuscript.

\section{References}

1 Guidelines for the use of growth hormone in children with short stature. A report by the Drug and Therapeutics Committee of the Lawson Wilkins Pediatric Endocrine Society. J Pediatr. 1995 Dec;127(6):857-67.

2 Wilkins L. The diagnosis and treatment of endocrine disorders in childhood and adolescence. Springfield (Illinois): Charles C. Thomas Verlag; 1966.

3 Recker BF. Reference charts used frequently by endocrinologists in assessing the growth and development of youth. In: Lifshitz F, editor. Pediatric endocrinology. New York: Marcel Dekker; 1996. pp. 887-932.

4 Pearson VV. Genetics. In: Gunn V, Nechyba C, editors. The Johns Hopkins Hospital Harriet Lane Handbook. Toronto: Mosby; 2002. p. 277.
5 Turan S, Bereket A, Omar A, Berber M, Ozen A, Bekiroglu N. Upper segment/lower segment ratio and armspan-height difference in healthy Turkish children. Acta Paediatr. 2005 Apr;94(4):407-13.

6 Tanner JM, Whitehouse RH, Hughes PC, Carter BS. Relative importance of growth hormone and sex steroids for the growth at puberty of trunk length, limb length, and muscle width in growth hormone-deficient children. J Pediatr. 1976 Dec;89(6):1000-8.

7 Prader A, Largo RH, Molinari L, Issler C. Physical growth of Swiss children from birth to 20 years of age. First Zurich longitudinal study of growth and development. Helv Paediatr Acta Suppl. 1989 Jun;52:1125.
8 Fredriks AM, van Buuren S, van Heel WJ, Dijkman-Neerincx RH, Verloove-Vanhorick SP, Wit JM. Nationwide age references for sitting height, leg length, and sitting height/ height ratio, and their diagnostic value for disproportionate growth disorders. Arch Dis Child. 2005 Aug;90(8):807-12.

9 de Arriba Muñoz A, Domínguez Cajal M, Rueda Caballero C, Labarta Aizpún JI, Mayayo Dehesa E, Ferrández Longás Á. Sitting height/standing height ratio in a Spanish population from birth to adulthood. Arch Argent Pediatr. 2013 Jul-Aug;111(4):309-14.

10 Bundak R, Bas F, Furman A, Günöz H, Darendeliler F, Saka N, et al. Sitting height and sitting height/height ratio references for Turkish children. Eur J Pediatr. 2014 Jul; 173(7):861-9. 
11 Zhang YQ, Li H. Reference charts of sitting height, leg length and body proportions for Chinese children aged 0-18 years. Ann Hum Biol. 2015;42(3):223-30.

12 Rappold G, Blum WF, Shavrikova EP, Crowe BJ, Roeth R, Quigley CA, et al. Genotypes and phenotypes in children with short stature: clinical indicators of SHOX haploinsufficiency. J Med Genet. 2007 May;44(5):306-13.

13 Gerver WJ, de Bruin R. Paediatric morphometrics: a reference manual (second extended edition). Maastricht: University Press Maastricht; 2001

14 Loeys BL, Dietz HC, Braverman AC, Callewaert BL, De Backer J, Devereux RB, et al. The revised Ghent nosology for the Marfan syndrome. J Med Genet. 2010 Jul;47(7):476-85.
15 Quanjer PH, Capderou A, Mazicioglu MM, Aggarwal AN, Banik SD, Popovic S, et al. Allage relationship between arm span and height in different ethnic groups. Eur Respir J. 2014 Oct;44(4):905-12.

16 Gkourogianni A, Andrew M, Tyzinski L, Crocker M, Douglas J, Dunbar N, et al. Clinical Characterization of Patients with Autosomal Dominant Short Stature due to Aggrecan Mutations. J Clin Endocrinol Metab. 2017 Feb;102(2):460-9.

17 Gerver WJ, de Bruin R. Growth velocity: a presentation of reference values in Dutch children. Horm Res. 2003;60(4):181-4.

18 Gerver WJ, vd Laan CG, Drayer NM, Schaafsma W. Smoothing techniques for obtaining reference values for measurements of children. Int J Biomed Comput. 1985 Jan;16(1):29-34.
19 Wit JM, Kamp GA, Oostdijk W; on behalf of the Dutch Working Group on Triage and Diagnosis of Growth Disorders in Children. Towards a Rational and Efficient Diagnostic Approach in Children Referred for Growth Failure to the General Paediatrician. Horm Res Paediatr. 2019;91(4):223-40.

20 Jee YH, Andrade AC, Baron J, Nilsson O. Genetics of Short Stature. Endocrinol Metab Clin North Am. 2017 Jun;46(2):259-81.

21 Oostdijk W, Idkowiak J, Mueller JW, House PJ, Taylor AE, O'Reilly MW, et al. PAPSS2 deficiency causes androgen excess via impaired DHEA sulfation - in vitro and in vivo studies in a family harboring two novel PAPSS2 mutations. J Clin Endocrinol Metab. 2015 Apr; 100(4):E672-80. 